\title{
La dignidad y el sentido. Narrativa audiovisual y enfermedad mental en It's such a beautiful day (Don Hertzfeldt, 2012)'
}

\section{Dignity and meaning. Film narrative and mental disorders in It's such a beautiful day (Don Hertzfeldt, 2012)}

\author{
Aarón Rodríguez Serrano. Universitat Jaume I (serranoa@uji.es)
}

Recibido: 11-V-2015 - Aceptado: 10-VII-2015

Resumen:

El presente trabajo pretende proponer un análisis de la cinta It's such a beautiful day (Don Hertzfeldt, 2012), al trasluz de las relaciones que se establecen entre narrativa fílmica y enfermedad mental. Se trata de un objeto de estudio novedoso, ya que es el primero que se publica en castellano sobre dicha película, y además, propone algunas variaciones metodológicas sustanciales sobre la aproximación que desde el análisis fílmico se pueden realizar a propósito del tratamiento visual de la enfermedad. Para ello, se utilizarán las herramientas habituales del estudio narratológico del film, incorporando además aquellos préstamos de la filosofía del siglo XX especialmente relevantes por su relación con la experiencia de la realidad y sus quiebras. El artículo está estructurado mediante una introducción y una serie de clarificaciones metodológicas que posteriormente permiten analizar con cierta profundidad tres grandes apartados narrativos: en primer lugar, las relaciones que se establecen entre espacio y tiempo fílmico y enfermedad mental. En segundo lugar, la estructura tripartita y no lineal de la cinta, con sus correspondientes núcleos de significación narrativos. Por último, el complejo sistema enunciativo de la película, con el desglose de la problemática de su sistema de narradores.

Palabras clave:

Análisis Fílmico; Narrativa Audiovisual; Enfermedad mental; It’s such a beautiful day; Don Hertzfeldt.

Abstract:

Our paper tries to propose a concrete analysis of the movie It's such a beautiful day (Don Hertzfeldt, 2012), exploring the connections between the movie's narrative and the mental disorder. It's a relevant object of study for, at least, two main reasons: In the first place, it's the first analysis of the movie published in Spanish. In the second place, it offers a new perspective in the relations between film analysis and mental disorders. In order to achieve our goal, we will combine two different kind of analytical tools: the classical techniques developed by the narratology studies and some of the most relevant parameters of the philosophical production of the XXth century-specifically, the ones related with the treatment of the reality and his phenomenological doubts. The paper is structured in three main narrative sections: A. The relations between space, time and mental disorder. B. The broken structure of the movie, with the different narrative cores and C. The enunciation system of the movie and its own system of narrators.

Keywords:

Film Analysis; Film Narrative; Mental disorder; It's such a beautiful day; Don Hertzfeldt.

1 El presente trabajo ha sido realizado en el marco del Proyecto de Investigación “La crisis de lo real: la representación documental e informativa en el entorno de la crisis financiera global” (P1·1A2014-05), financiado por la Universitat Jaume I, a través de la convocatoria competitiva de proyectos de investigación de la UJI (evaluados en 2014 por la Agència per a la Qualitat del Sistema Universitari de Catalunya, AQU), para el periodo 2014-2017, bajo la dirección de Javier Marzal Felici. 


\section{Introducción}

Sabemos que desde su inicio mismo, la captación fotográfica de enfermos mentales generó una suerte de fascinación, de escoptofilia del exceso y del vértigo. Desde el departamento fotográfico que retrataba a las histéricas de La Salpêtrière (Didi-Huberman, 2007) hasta los primeros registros audiovisuales que se demoraban en la contemplación de los enfermos (Cueto, 2005) pasando por la terrible instrumentalización ideológica acometida por el III Reich (Burleigh, 1994; Goetz, 2014), asoma el riesgo de la banalización, de la perversión, de la mirada que puede quedar atrapada de alguna manera en la alteridad con la que se presenta la enfermedad mental. Cuando Raymond Bellour compara las fotografías de las histéricas con el nacimiento del cine y el auge del espiritismo (Bellour, 2013: 45), en realidad está apuntando con absoluta claridad al temblor, a ese "plus de significado" ético que impone el cuerpo diferente, el cuerpo de un Otro en el que se encierra un enigma que no podemos descifrar. El primer plano del enfermo, o del cadáver, o de aquel que sufre, es algo más que un simple recurso audiovisual. Antes bien, entraña una pregunta -la de su sentido-, pero también puede exigir una responsabilidad individual y colectiva. Estudios como el realizado por Georges Didi-Huberman sobre las fotografías de los ancianos convalecientes tomadas por Phillipe Bazin nos recuerdan la importancia de las conexiones que se establecen entre el cuerpo enfermo y la mirada. El autor señala dos riesgos que asoman en cada decisión estética: "la subexposición, la censura, el abandono, el desprecio, y luego en la sobreexposición, el espectáculo, la piedad mal entendida, el humanitarismo gestionado con cinismo" (Didi-Huberman, 2014: 31).

Parecería, por tanto, que retratar a ese Otro es una cuestión de posición ética. Tan peligroso es, por lo tanto, borrar de la imagen aquello que nos incomoda precisamente por su otredad, como exponerlo espectacularmente para intentar extraer de su contemplación impostadas reacciones humanitarias o pueriles efectos de fascinación. Retratar al enfermo con dignidad parece exigir hacerse cargo de su situación, plantear una distancia narrativa que no busque la identificación ni la empatía gratuita, levantar acta de su dolor como rasgo de un discurso y no como motor del mismo. El enfermo retratado es a la vez un sujeto único -fragilidad, fisicidad, materia frente a la cámara-, pero también una cierta encarnación de una idea general -la de enfermedad, o la de salud, o en el límite, incluso la de sociedad. Cuando Ruiz de Samaniego afirma que "el arte atestigua en cada civilización o momento histórico una concepción y una realidad distinta con el cuerpo y los espacios y signos de cierta enfermedad” (2015: 105) no solo está utilizando una fórmula heredera de Foucault (1978) para topografiar las relaciones entre arte y enfermedad, sino que además nos recuerda que cada momento histórico mira al cuerpo enfermo desde una perspectiva propia, herida de su propia circunstancia. La evolución de la mirada hacia el enfermo mental o hacia las instituciones que lo cobijan (Poseck, 2007) no es una simple cuestión vinculada con la historiografía del cine, sino antes bien, un gesto de cuestionamiento de la sociedad que genera y recibe esa mirada.

De ahí que el objetivo principal de nuestro artículo sea, dicho escuetamente, preguntarse por las relaciones entre narrativa cinematográfica y construcción audiovisual de la enfermedad mental, valiéndonos para ello de un texto concreto en 
el que creemos que se respeta, de manera original y estrictamente fílmica, esa suerte de distancia ética y también esa dualidad entre empatía (subjetiva) y visión social (compartida). El hecho de escoger como objeto de estudio It's such a beatiful day (Don Hertzfeldt, 2012) responde, por lo tanto, tanto a un enfoque rigurosamente ético -que, esperamos, quede bien justificada en el análisis posterior- como a la voluntad de comenzar a reflexionar sobre la obra de un director que, hasta el momento, ha sido prácticamente ninguneado en los debates académicos contemporáneos.

La obra de Hertzfeldt, en el momento de redactar estas líneas, ha sido estudiada de manera puramente anecdótica, reducida a sus elementos estrictamente técnicos (Kunz, 2012: 62), o situada como ejemplo de nuevas voces contemporáneas en el terreno de la animación (Thys, 2013). Quizá ha sido víctima de ese habitual prejuicio contra los dibujos animados para adultos que hunde sus raíces en las teorías realistas de Sigfried Kracauer (1989) y que se hunde en todos los procesos del acontecimiento cinematográfico:

Combatir el prejuicio establecido que limita el dibujo animado a un tipo de público eminentemente infantil no resulta tarea fácil, y si a eso añadimos la incomprensión y desconfianza por parte de los productores, la difusión y realización de las obras animadas para adultos conduce cada vez más al vacío (Yébenes, 2002: 137).

La cita no resulta baladí, en tanto radiografía a la perfección el paupérrimo estado académico y económico de la obra de Hertzfeldt: pese a la innumerable colección de galardones cosechados en decenas de festivales en los últimos quince años -incluyendo una nominación al Óscar de la Academia por su pieza Rejected (2000)-, el autor trabaja de manera absolutamente independiente, al margen de cualquier estudio y cualquier distribuidora, ofreciendo sus contenidos a través de plataformas on-line de pago.

Nuestro trabajo, ante la imposibilidad de dar cuenta de la riqueza y complejidad de los mecanismos formales que se despliegan a lo largo de toda su filmografía, ha decidido centrarse en su célebre tríptico sobre la enfermedad mental².

\section{Apuntes metodológicos y estructura}

La enfermedad mental en el cine ha sido tradicionalmente estudiada desde perspectivas estrictamente heredadas de la teoría literaria: bien desde su capacidad para generar o desactivar estigmas (Muñoz \& Uriarte, 2006), o bien desde su posibilidad para exponer con mayor o menor verosimilitud ciertas psicopatologías mediante la mostración en pantalla de conductas concretas (Moreno Martin, 2003; Vera Poseck, 2006; Wedding, Boyd, \& Niemiec, 2005). Sin embargo, como bien señaló Jonathan Rosenbaum (2010: 82), es necesario no trabajar únicamente sobre los parámetros de relato estrictamente

It's such a beautiful day es la compilación, realizada por el propio autor, de tres cortometrajes anteriores: Everything will be OK (2006), I am so proud of you (2008) y el homónimo It's such a beautiful day (2011). Como veremos posteriormente, esta división tripartita será crucial para entender algunos de los elementos claves de significación en la construcción del relato. 
literarios, sino ampliar los terrenos analizables para incorporar aquello que constituye lo específicamente cinematográfico. Dicho con otras palabras y conduciendo el argumento a nuestro campo concreto, no basta con explicar cómo los personajes representan o encarnan hipotéticas realidades sobre la enfermedad mental. Antes bien, es crucial comprender cómo los mecanismos de "puesta en forma" cinematográfica generan una experiencia determinada al respecto ${ }^{3}$.

El concepto de experiencia resulta clave para poder orientar los elementos metodológicos de nuestro análisis. Si bien teorías formalistas como la de David Bordwell (1995) resultaron claves para reivindicar la importancia de los elementos de significación fílmica, recientes trabajos desde el ámbito de la semiótica (Zumalde, 2011) o incluso de la fenomenología cinematográfica (Esqueda Verano y Cuevas Álvarez, 2012) han redondeado los postulados iniciales para introducir unos márgenes asibles en el encaramiento con el texto.

Estas herramientas resultan fundamentales en tanto It's such a beautiful day bloquea desde el primer minuto la imposibilidad de ser utilizado como una simple mostración cinematográfica de una patología concreta. Y esto es así porque la enfermedad de Bill -el protagonista- no aparece nunca explícitamente mencionada en la cinta. Lo que podría ser considerado como un ataque directo contra los mecanismos tradicionales de verosimilitud narrativa es, en realidad, una arriesgada apuesta para convertir a la enfermedad mental como una suerte de circunstancia de dislocación total frente a la recepción normativa del mundo. Ciertamente, Bill muestra un cuadro sintomático en el que se pueden apreciar distintos rasgos que coincidirían tanto con las alucinaciones auditivas y visuales psicóticas (Cullberg, 2007), los trastornos disociativos vinculados con el tiempo o el espacio (Hart, Nijenhuis, \& Steele, 2008) o la modificación inconsciente de los recuerdos. Desde un punto de vista estrictamente clínico, la historia de Bill no puede servir para ilustrar ninguna enfermedad concreta. Antes bien, el valor de la cinta reside precisamente en convertir a su protagonista, como ya veremos, en una suerte de significante total de la enfermedad mental y de sus circunstancias sociales y familiares.

Por lo tanto, lo más sensato parece sin duda proponer un análisis construido sobre varios ejes discursivos exclusivamente aplicados a la narratología fílmica. En primer lugar, utilizaremos los aparatajes claves de la teoría narratológica clásica sobre espacio, tiempo, estructura e instancias narradoras tal y como aparecen formuladas, por ejemplo, en los textos ya canónicos de Gaudreault y Jost (1995) y en sus actualizaciones contemporáneas realizadas, entre otros, por Francisco Javier Gómez Tarín (2011). Del mismo modo, cada uno de los epígrafes contará con pequeños microanálisis concretos que permitirán profundizar desde el propio texto en las afirmaciones teóricas iniciales.

Sobre el concepto de "puesta en forma", remitimos al lector a los clarificadores trabajos realizados por Imanol Zumalde al respecto (2002 y 2006). Su particular y lúcida reivindicación de una semiótica afilada que pase por encima de los lugares menos afortunados de la teoría postestructuralista. 


\section{Análisis narrativo de It's such a beautiful day}

Como ya se ha señalado, It's such a beautiful day es una compilación de tres cortometrajes previos desarrollados en un espacio de seis años. Sin embargo, la cohesión entre los tres fragmentos, al menos en términos estrictamente formales, es total. Los tres episodios giran en torno al universo habitado por Bill, escindiéndose constantemente entre sus recuerdos, sus alucinaciones, sus sueños y los acontecimientos de un resbaladizo presente que en ningún momento queda cómodamente acotado. En lugar de eso, Bill es un sujeto anónimo que habita una ciudad del primer mundo en algún momento comprendido en las últimas décadas. Hertzfeldt parece poner especial cuidado en no permitir que elementos tecnológicos anclen claramente la narración a nuestro presente: Bill no tiene teléfono móvil, ni conexión a Internet, sino tan sólo pantallas de televisión, un contestador automático, material de oficina... Únicamente podemos situar el origen del relato como posterior a 1994 gracias a unas zapatillas irónicamente conectadas con otra película de animación de la factoría Disney: El rey león (The lion King, Roger Allers y Rob Minkoff, 1994).

\subsection{Consideraciones iniciales sobre la diégesis (I): Espacio narrativo}

Por otra parte, la división espacial tampoco ofrece grandes rasgos identitarios. Sabemos que los orígenes de Bill por parte materna se encuentran en Bootlag, pueblo localizado en Wyoming, pero no en qué ciudad habita ahora ni cuáles componen su recorrido final por el país. Antes bien, Hertzfeldt parece estar más interesado en trabajar el lugar de la acción desde una lógica mostrativa poco definida, entre la universalidad y la despersonalización. Así, los lugares se desvelarán desde los primeros minutos o bien como sugerencias visuales o bien como enormes espacios despersonalizados que recuerdan a la vieja categoría de los "no-lugares" postmodernos (Augé, 2005), espacios borrados de subjetividad en los que la experiencia conjurada tiende a ser homogenizada y borrada.

Tomemos como ejemplo de "sugerencia visual espacial" el arranque mismo de la cinta. Desde el negro inicial, sin que se imprima sobre la pantalla crédito de productora alguna, se desvela una imagen:

Fig. 01: It's such a beautiful day (Don Hertzfeldt, 2012)

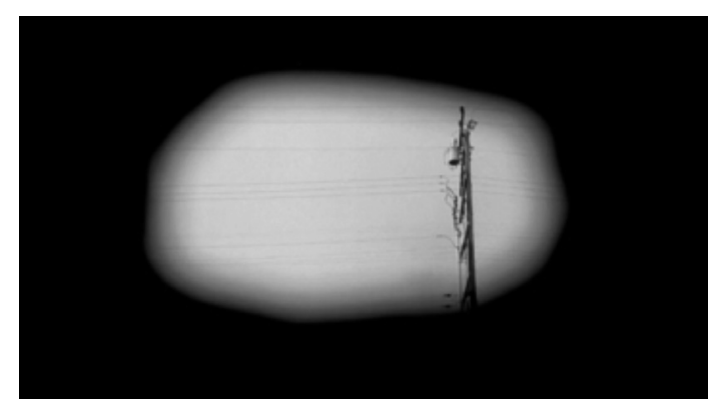

doxa.comunicación | n²1, pp. 113-132 | 117 
Se trata de una fotografía en blanco y negro que muestra, mediante un contrapicado, un poste telefónico. Sin embargo, no llena la pantalla, sino que parece generar una mancha en el centro mismo de la imagen. La fotografía tiembla, se superpone rápidamente a otras fotografías estáticas generando una suerte de sensación de movimiento intermitente. El montaje de distintos fotogramas estáticos parece sugerir un movimiento de cámara de izquierda a derecha, que a su vez está puntuado por los primeros compases de una interpretación especialmente vivaz del Moldeau de Bedrïch Smetana.

Hertzfeldt, gracias al efecto de caché sobre el marco visual, el movimiento ininterrumpido y el uso del blanco y negro, comienza sugiriendo una deuda con el cine anterior al Modo de Representación Institucional (Burch, 1987). Sin embargo, la angulación de cámara -que, al contrario de lo que ocurría en aquel momento, no muestra un encuadre centrípeto, frontal, con una escenografía delimitada (Vila, 1997)- así como el propio acompañamiento musical, parecen apuntar en otra dirección. Hertzfeldt, sin duda, está remitiendo a la construcción visual propia de autores postmodernos como Guy Maddin y sus procesos de "rehabilitar los lenguajes cinematográficos perdidos" (Straw, 2002: 305). La composición musical de Smetana, a su vez, genera impresión de levedad y movimiento mediante la superposición de la melodía a cargo de una flauta travesera punteada por los agudos de los violines en pizzicato.

Acto seguido, y utilizando un nuevo caché, Hertzfeldt introduce en pantalla a Bill, siguiendo también la misma dirección en movimiento interno de plano de izquierda a derecha.

Fig. 02: It's such a beautiful day (Don Hertzfeldt, 2012)

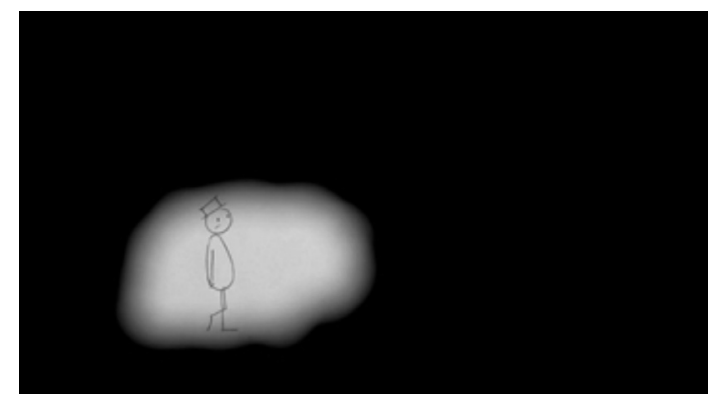

Merece la pena señalar al menos dos rasgos básicos. El primero es que no hay ninguna conexión espacial real entre la figura 01 y la figura 02 , más allá de su contigüidad temporal lógica en el montaje y la rima de movimiento sugerida entre ambos fragmentos. Dicho con mayor claridad: no sabemos si los postes de teléfono corresponden a la calle por la que transita Bill, a una visión interior del propio personaje, a su delirio o simplemente a una marca visible de la enunciación. En segundo lugar, el universo en el que habita Bill está completamente despojado de cualquier elemento escenográfico. Su cuerpo, paradójico y breve incluso para tratarse de un personaje animado, parece flotar sobre el blanco de un papel. 
La ausencia de escenografía es un rasgo fundamental de una gran parte de la producción de Hertzfeldt. En el caso de It's such a beautiful day, la técnica es todavía más sangrante de lo habitual en tanto los personajes se deslizan por un vacío espacial que tiene dos niveles de horror dialéctica y plásticamente opuestos: el blanco de la superficie sobre la que se deslizan y el negro profundo del caché que les encierra en el encuadre. Al contrario de lo que ocurre en una parte importante del cine contemporáneo, el Meganarrador prescinde voluntariamente de cualquier lógica escénica ${ }^{4}$ para, como señalábamos antes, depurar el contexto espacial mediante simples sugerencias visuales.

\subsection{Consideraciones iniciales sobre la diégesis (II): Tiempo narrativo}

Al igual que ocurría con el espacio, el planteamiento temporal en It's such a beautiful day está muy lejos de plegarse a los rasgos del relato clásico. Podría pensarse que la división tripartita gracias a los tres mediometrajes seminales podría coincidir, de alguna manera, con el esquema tradicional de la narración dramática (Aristóteles, 1974), o con sus correspondientes actualizaciones cinematográficas (Sánchez-Escalonilla, 2001; Vogler, 2002). Nada más lejos de la realidad. En realidad, la apuesta de Hertzfeldt pertenece por derecho propio a esa categoría que Robert Mckee bautizó como Antiestructura o antitrama: "casualidad, tiempo no lineal y realidades incoherentes" (2002: 68).

Aunque en el siguiente epígrafe acometeremos el análisis detallado de cada una de las divisiones tripartitas, podemos adelantar que el conjunto de la cinta funciona más bien como una suerte de caótica superposición de eventos vertiginosos en los que se enhebran distintas fases de la enfermedad mental. Situaciones aparentemente banales de la vida cotidiana se extienden durante minutos de metraje, mientras que días enteros de convalecencia o supuestos gestos épicos son despachados en cuestión de segundos. El tiempo de la cinta es, digámoslo de una vez, el tiempo quebrado de la enfermedad mental. Los sucesos se retratan principalmente desde el punto de vista emocional de Bill, desde su sensibilidad y sus implicaciones en el proceso irreversible de la misma. Es imposible hablar de linealidad temporal o de causalidad cronológica cuando la enfermedad -o mejor dicho, el intento de transmitir fílmicamente su significación emocional- desordenan las vivencias del enfermo y las superpone en una suerte de crisol de rostros, sentimientos y alucinaciones.

Pongamos dos ejemplos de ese tipo de "dislocación del tiempo fílmico" que Hertzfeldt pretende compartir con el espectador. En primer lugar, encontramos un plano que retrata el camino al trabajo en autobús tras una de las crisis de Bill. Se trata de un único encuadre de más de un minuto de duración en el que nuestro protagonista contempla silenciosamente

Remitimos al trabajo desarrollado por Shaila García Catalá y Teresa Sorolla Romero (2014), en el que analizan con gran precisión la manera en la que distintos Meganarradores se valen de la construcción espacial precisamente para manifestarse o para generar distintos efectos de sentido narrativo. 
la lluvia. Tras él, se escucha un fragmento posterior de la composición de Smetana que remite, a su vez, al prólogo de $E l$ oro del Rhin, la primera parte de la tetralogía del anillo de Richard Wagner 5 .

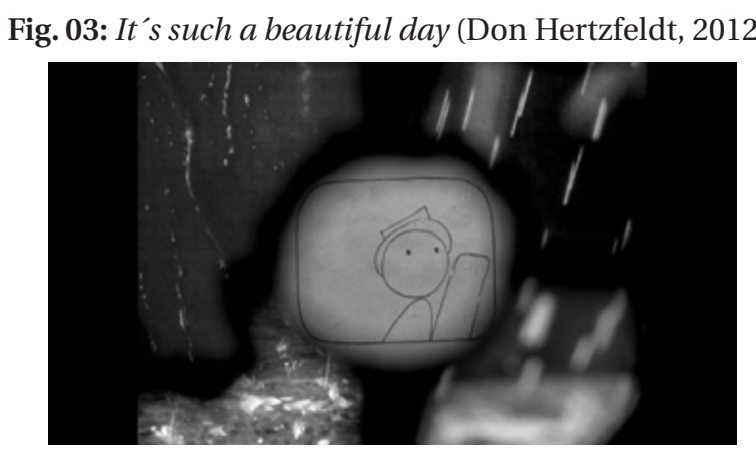

En un uso realmente notable del tiempo muerto cinematográfico, Hertzfeldt detiene la narración para que podamos experimentar de manera absolutamente empática la mirada misma del protagonista. Bill emerge del Hospital, en el que ha experimentado una situación crítica -el propio narrador nos informa de que su madre llegó a comprar un ataúd para sus restos-y el hecho mismo de estar vivo, de intentar regresar a una rutina que le permita dotar de sentido a sus actividades, es traducido en el ejercicio de la extensión del tiempo fílmico. Sin embargo, como es bien sabido, la detención voluntaria del tiempo narrativo a favor de un tiempo contemplativo no siempre tiene este tipo de efectos positivos. Antes bien, el tiempo también queda congelado en señal de duelo, de duda o de respeto. En otro momento de la cinta, Bill escucha en el contestador automático la voz de su médico avisándole de que le queda poco tiempo de vida. Como respuesta, Hertzfeldt detiene de nuevo la acción y nos muestra a un Bill estático durante varios segundos, mirando al vacío.

5 Las relaciones entre la obra de Hertzfeldt y el compositor Richard Wagner son bastante más complejas de lo que pudiera parece tras un primer vistazo. It's such a beautiful day cita, de manera controladamente descontextualizada, diversos fragmentos de El oro del Rhin y el Im treibhaus de las Wesendonk Lieder. En este fragmento concreto, los compases citados Smetana repiten el efecto compositivo del prólogo de El oro del Rhin, proponiendo una hermosa pintura musical de la ascensión desde las aguas, de la creación del mundo y el descubrimiento mismo de la luz (Bernard Shaw, 2011: 179). El director se vale aquí de la cita para generar una rima visual con la lluvia que cae sobre el autobús, la luz que se filtra entre los cristales, y a su vez, la mirada del protagonista que se recrea en el sorprendente milagro de lo cotidiano tras la tragedia. 
Fig. 04: It's such a beautiful day (Don Hertzfeldt, 2012)

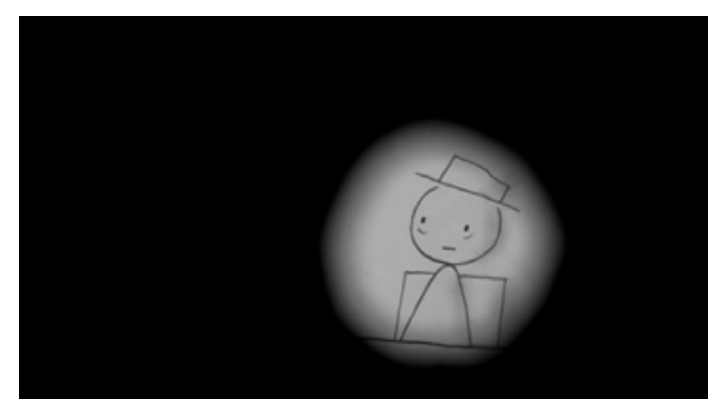

El gesto de Bill resulta indescifrable. En esta ocasión, no hay música que acompañe a semejante descubrimiento. Simplemente podemos contemplar esas dos marcas bajo los ojos, ojeras que anticipan el cansancio, el desvelo y el humilde fracaso del enfermo que comprende que ha perdido definitivamente la batalla. Hertzfeldt detiene el tiempo precisamente como señal de duelo, como respuesta cinematográfica a lo imposible de hacerse cargo del mensaje depositado en el contestador automático. Deja un espacio de la narración en la calma tensa del respeto y de la muerte, generando así un tiempo fílmico para la dignidad en el que espectador y personaje pueden, de alguna manera, compartir ese momento sagrado.

\subsection{Desarrollo de la estructura}

Así pues, podemos señalar que el director realiza un uso doble del tiempo de marcado carácter antinaturalista: o bien mediante la superposición caótica de pequeños gestos cotidianos, o bien mediante su detención dramática para explorar la profundidad emocional de cada secuencia. A su vez, esta colección de fragmentos se enhebra en las tres divisiones mayores de la cinta, correspondiente a los tres mediometrajes que la componen. Aunque, como bien señalábamos hace unos párrafos, It's such a beautiful day esté dispuesto con forma antitramática, no deja de ser cierto que se pueden realizar algunas sugerencias sobre los núcleos temáticos sobre los que el director ordena los acontecimientos.

\subsubsection{Primer fragmento: Everything will be $\mathrm{OK}$}

Así, por ejemplo, el primer fragmento está dedicado principalmente a la exposición de la vida cotidiana de Bill, los primeros síntomas de su enfermedad y la descripción más o menos detallada de su primera gran crisis tras un cambio de medicación. Aunque correspondería con el pórtico del relato, no se puede hablar propiamente ni de "llamada de la aventura" (Campbell, 2005: 53) ni de “separación” o “prohibición” (Propp, 1974: 45-49; 2007: 38). Tampoco parece sensato aplicar herramientas referentes a la presentación sistemática del mundo o de sus normas diegéticas (Field, 2001: 53-64), sino antes bien, atender a la especificidad de las pistas sobre las que se desarrolla la experiencia misma de la enfermedad mental. 
Dicho todavía con mayor claridad: si por su propia naturaleza temporal caótica -nos sentamos tentados de acuñar la etiqueta "rizomática" - resulta prácticamente imposible esbozar la linealidad de los acontecimientos para dotarlos de un sentido, no es menos cierto que los vórtices del malestar de Bill son señalados por Hertzfeldt durante los primeros minutos con toda claridad.

En primer lugar, Bill es posicionado claramente como un animal herido en los ejes de la comunicación, la intimidad y su propia aceptación de la enfermedad. La ciudad es presentada como un espacio abrasivo en el que ciudadanos completamente desconectados entre sí vagan dirigiéndose palabras parcas y fórmulas oxidadas, escuchando música horrible en el interior de sus coches, hacinados como pequeñas cápsulas de vida autosuficientes, frágiles, desconectadas. En el caso concreto del enfermo, se cumple con terrible claridad la profecía heideggeriana a propósito del espacio inhabitable, aquel en el que no se puede "conducir a los mortales a la esencia de la muerte" (Heidegger, 1994: 132, véase también Rodríguez Serrano, 2015). Bill vive preso entre lógicas de comportamientos indescifrables y alienantes, sin encontrar ningún tipo de asidero sobre el que construir una narrativa sobre su propia enfermedad. Nos encontramos en un territorio típico del cine postmoderno: el de las sociedades solipsistas:

La cultura narcisista es proclive a la masa, a la muchedumbre. Sin embargo, la gente en ella se siente muy sola. Esto es debido al individualismo rampante de nuestras sociedades del bienestar, que nos separa de la alteridad, a la vez que nos dificulta el acceso al propio sentido de la realidad (...) Nos convertimos en seres débiles y neuróticos inconscientes de nuestra propia fragilidad (Orellana y Martínez Lucena, 2010: 140).

La idea de la sociedad como algo que "dificulta el acceso al propio sentido de la realidad" es absolutamente primordial en el primer tercio de la cinta. Máxime cuando, como sabemos, la enfermedad en general -pero mucho más concretamente la enfermedad mental- es una lucha constante por la búsqueda de sentido (Zamora Marín, 2009), por la necesidad misma de simbolizar de alguna manera el sufrimiento. La sociedad, excluye mediante sus buenas intenciones o su silencio al enfermo. En el límite, lo infantiliza y lo convierte en una suerte de cuerpo "imperfecto" pero integrado bajo una cierta puerilidad tras la que late el profundo pánico que entraña su presencia en nuestros sistemas sociales. En It’s such a beautiful day encontramos una precisa formulación en el plano en el que Bill lee uno de esos prospectos informativos que están redactados y diseñados como enormes libros infantiles. 
Fig. 05: It's such a beautiful day (Don Hertzfeldt, 2012)

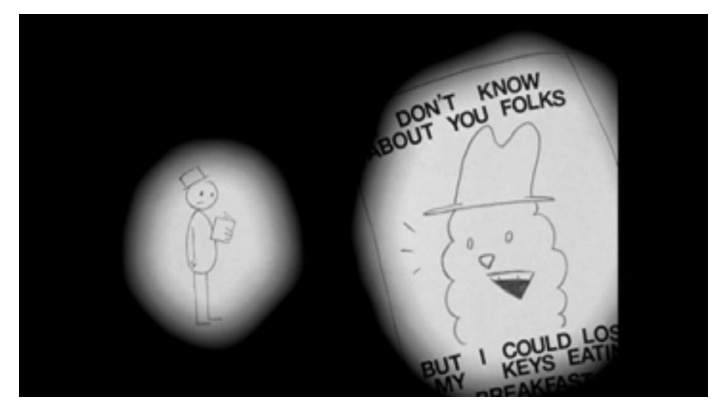

Al observar la figura 05 detectamos rápidamente el dramatismo que se anuda en todo este primer tercio de la cinta: El plano está escindido en dos mitades: la primera de ellas corresponde al protagonista. La segunda a su propia mirada. Bill está literalmente empequeñecido, desconectado, seccionado de esa caricatura de sí mismo -hay una rima entre ambos punteada por el sombrero y el trazo infantil- que muestra visualmente su empequeñecimiento como enfermo. La portada reza: I don't know about you, folks, but I could lose my keys eating breakfast! (Yo no sé vosotros, muchachos, pero yo podría perder mis propias llaves desayunando). El gesto es absolutamente cruel, en tanto la idea social de lo que se espera del enfermo (levedad, alegría, sentido del humor, una franca sonrisa, un código controlable de conducta) resulta absolutamente inaplicable en el caso de Bill. El personaje caricaturesco es notablemente más grande, más presente en el marco general de la imagen, casi como si pudiera fagocitar tranquilamente el cuerpo del hombre que le mira. Sin embargo, Hertzfeldt no permite que ese falso plano subjetivo escindido nos haga coincidir empáticamente del todo con el protagonista (Prósper Ribes, 2008), sino que en todo momento nos obliga a reflexionar sobre cómo Bill, humillado, experimenta el acto mismo de su mirada.

\subsubsection{Segundo fragmento: I'm so proud of you}

Si el primer fragmento estaba orientado principalmente a la mostración de los problemas sociológicos que acompañaban a la enfermedad, el segundo está dedicado casi íntegramente a la relación de Bill con su pasado. Si en el primer fragmento es el mundo exterior el que resulta extrañamente ajeno, inhabitable, aquí es en contraposición el mundo interior el que se vuelve hostil, amenazador. De hecho, el tiempo se manifiesta como prácticamente incontrolable en tres campos muy concretos: el tiempo estrictamente fílmico (mediante la quiebra del relato con constantes saltos temporales hacia distintos lugares del pasado difusamente conectados entre sí), el tiempo interior de los recuerdos de Bill (mediante la superposición de anécdotas familiares de dudosa verosimilitud que, como veremos más adelante, son generadas por la propia imaginación del protagonista) y una demoledora ruptura final del tiempo ontológico mismo, a medio camino entre la duración (durée) de Bergson (1925) y la quiebra de los parámetros estrictamente físicos con los que aparentemente se 
conforma nuestra experiencia de lo real. Podemos localizar esta tensión, por ejemplo, en uno de los momentos en los que el narrador nos informa:

A la hora del almuerzo, [un compañero] habló con Bill sobre un libro de Física que estaba leyendo, un libro que trataba del tiempo. El paso del tiempo era simplemente una ilusión, ya que toda la eternidad está realmente ocurriendo al mismo tiempo, a la vez. El pasado nunca se desvanece, y el futuro ya ha ocurrido. Toda la historia está pensada y dirigida, como un paisaje infinito de eventos simultáneos, que simplemente parecen desplazarse en una única dirección. Bill bromeó diciendo que habría jurado que había oído eso antes, pero su compañero le miró como si fuera incapaz de entenderlo ${ }^{6}$.

Ciertamente, la parábola planteada por Hertzfeldt apunta en sordina a los descubrimientos recientes de la física cuántica en torno a las relaciones entre espacio, tiempo y velocidad de la luz (Chown, 2007: 82), pero no únicamente para justificar sus digresiones narrativas o su quiebra estructural en torno a la falta de coherencia y verosimilitud del universo ${ }^{7}$, sino también para explicar de manera concreta y demoledora hasta qué punto Bill no es consciente de cómo su enfermedad mental se vale de su percepción misma de lo temporal para distorsionar su mundo y, como consecuencia, su relación con los demás.

Sin ánimo de agotar la cuestión, diremos que el planteamiento del pasado que sobrevuela en It's such a beautiful day señala la herencia de la enfermedad mental. Bill construye toda una narrativa caótica, proporcionada por el propio narrador omnisciente del relato, en torno a sus antecedentes familiares. Ancestros homicidas, torturados por visiones fantasmagóricas, presos de delirios de todo tipo que surgen de la narrativa folk norteamericana y acaban desembocando en lo que no es sino un aullido de desgarrador desamparo. I am so proud of you (Estoy tan orgullosa de ti), título original del fragmento, es una referencia directa a la nota que la madre de Bill depositaba en sus enseres escolares, el extraño mensaje cifrado que le mandaba a través de su propia locura para dotarle de un asidero frente al mundo.

6 Traducción del autor.

7 Hay una serie de trabajos desarrollados por José Antonio Palao Errando que ayudan a reforzar esta idea y la complementan. Si desde la década pasada ya comenzó a desbrozar las relaciones en crisis entre la (in)seguridad de los acontecimientos del mundo -o si se prefiere, del discurso dominante de la técnica- y la quiebra de los parámetros narrativos tradicionales (Palao Errando, 2008), más recientemente ha propuesto dos exploraciones especialmente brillantes en torno a la manera en la que las distintas tramas narrativas se pueden unificar en un Hipernúcleo de sentido (Palao Errando, 2013). Por el momento, baste señalar que la gran desesperación que plantea Hertzfeldt en It's such a beautiful day es, muy precisamente, que la enfermedad mental destruye cualquier capacidad para poder anudar ese Hipernúcleo de sentido que necesita el sujeto. De hecho, y sin miedo alguno de volver una vez más a Heidegger -"Desde nuestro punto de vista, la esencia de la técnica no es nada humano" (2005: 81)-, el gran fracaso de la técnica ha sido precisamente su incapacidad para dotar de sentido a aquellos relatos íntimos (relatos del tiempo vivido, del tiempo imaginado y del tiempo soñado) que habían estallado a pedazos. De ahí que, lógicamente, la decisión ética y estética del director no pueda ser otra que optar por una quiebra absoluta de los mecanismos de continuidad, linealidad y verosimilitud que mantendrían ese doble espejismo: el del mundo habitable (el tiempo habitable) y el del film construido lógicamente. 
Bill, sea cual sea su pasado, lo ha reconstruido hasta generar un pasaje desolado: un hermano muerto en el mar, un padre desquiciado que abandonó la casa familiar -otro lugar común habitual del malestar en el cine postmoderno (Rodríguez Serrano, 2010)-y, finalmente, una narrativa de angustia que alcanza su cénit al descubrir el expediente médico de su madre y la recomendación facultativa de no tener hijos.

Llegando ya al corazón de este segundo fragmento, si anteriormente se demostró que Bill no podía habitar el mundo, ahora parece evidente que tampoco puede habitar su propia historia, su propio relato. Está literalmente arrancado de su propio lugar en el mundo, ese lugar simbólico y antropológico que se construye mediante las narrativas familiares. No está de más recordar, llegados a este punto, una hermosa cita de González Requena:

Nada tan imprescindible para el nuevo ser destinado a afrontar esa travesía por lo real que la promesa de que es posible un futuro digno que le aguarda (...) Sólo si los padres afrontan su angustia y sustentan un -digno-relato, hacen posible que exista para el niño ese orden de trascendencia que es el orden mismo del sentido (2002: 119-120).

\subsubsection{Tercer fragmento: It's such a beautiful day}

Luego, sin posibilidad alguna de poder forjar esa narrativa interior/exterior, el tercer fragmento gira de manera directa en torno a la fase crítica de Bill y su enfrentamiento final con la muerte. Agonizando en un Hospital, siendo bombardeado por tratamientos intrusivos en los que en ningún momento se atisba un sentido, Bill es consciente de su propia existencia como cuerpo que sufre y de la experiencia misma del tiempo que se agota: si el anterior fragmento gira en torno a la imposible construcción de un pasado, el final de la cinta se proyecta en una parábola desmesurada hacia un futuro delirado en el que Bill, en el cénit de su delirio, imagina poder agotar el concepto mismo de la existencia: vivirlo todo, conocerlo todo, hablar todas las lenguas y, finalmente, sobrevivir más allá del tiempo mismo.

Delirio narcisista, sin duda, pero también respuesta desesperada y poética ante la limitación cognitiva y estrictamente física que imponía la enfermedad. Allí donde no se ha podido conocer porque el mundo llegaba a través de un filtro de sufrimiento, allí donde no se ha podido superar mediante el Otro la condición de arrojado, solo queda la fantasía de una totalidad grandiosa, de un infinito desmesurado en el que no se deba temer ni a la muerte ni a las propias barreras ontológicas que marca la mortalidad (Lévinas, 2012). No es de extrañar que la última frase que pronuncie el narrador sea, muy precisamente: "[Bill vive] hasta que el tiempo pierde todo significado (...), hasta que olvida su nombre y el lugar del que vino. Vive y vive hasta que se apagan todas las luces”8. Triple negación: negación del tiempo -fundamento ontológico mismo de la existencia, fundamento que permite la narración misma de lo humano por la vía de la asunción inevitable de la mortalidad (Heidegger, 2009: 253-283), negación de su nombre entendido como el proyecto mismo de ese tiempo his-

$8 \quad$ Traducción del autor. 
tórico vivido y experimentado, tiempo/lugar en el que habitaba la identidad familiar (Lacan, 2005), y por último, negación incluso de la luz entendida radicalmente como la cualidad misma del universo que permite conocer, habitar, existir (Lévinas, 2000: 59-66).

Pero por otra parte, no deja de ser hermoso que, precisamente el engranaje narrativo -el punto de giro de la estructuraque le permite a Bill dejar atrás todo el sufrimiento vivido y asumir plenamente la posibilidad de una emancipación, de una superación espiritual de los parámetros de la muerte, sea el encuentro final con el padre perdido. Una vez recibida la noticia de su desahucio, y generado ese doloroso tiempo muerto que analizábamos hace unas páginas, Bill se arroja en un accidentado viaje por carretera hasta encontrar, de manera casi azarosa y dominada por el velo mismo de la enfermedad, el asilo en el que dormita su padre. Hertzfeldt, ante el umbral mismo de la muerte, propone literalmente el perdón:

Bill entrega en la recepción un papel y aparece ante él un frágil anciano en silla de ruedas, un hombre que lleva allí más de diez años, pero al que nadie ha visitado. Ninguna de esas dos personas recuerda por qué está ahí, o quién es exactamente es la otra persona, pero se sientan a ver un programa de televisión juntos. Y cuando es la hora en la que Bill tiene que marcharse, se levanta y le dice algo hermoso: Estás perdonado. Ninguno de los dos entiende exactamente lo que significa, pero el anciano llora de todos modos. Nunca se volverán a ver9.

En primer lugar, es relevante que la construcción estética de plano cambie por completo tanto en su dimensión cromática como en la propia disposición de manchas en el encuadre.

Fig. 06: It's such a beautiful day (Don Hertzfeldt, 2012)

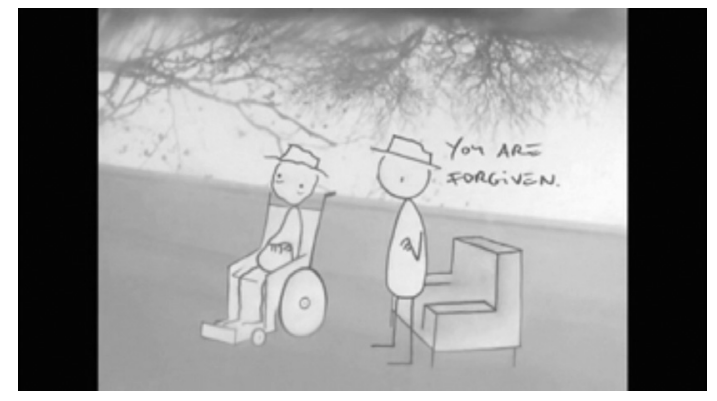

La caída final de Bill en la enfermedad tiene como efecto directo la desaparición de los cachés que convertían el plano en una colección de manchas, de espacios seccionados entre los que no parecía fluir ningún sentido. El fondo negro es sustituido ahora por potentes escenarios, generalmente fotografías sobre las que Bill interacciona. Los planos

$9 \quad$ Traducción del autor. 
correspondientes al asilo son, además, los más cálidos de la cinta, con una dominante anaranjada, crepuscular pero al mismo tiempo alentadora, en la que se envuelve esa idea de perdón y encuentro entre padre e hijo.

Y hay, además, un dato capital en este plano que nos permitirá entender plenamente el próximo y último epígrafe. You are forgiven (Estás perdonado) son las únicas palabras que únicamente pertenecen a Bill, que no son pronunciadas por el narrador en su nombre. Esas tres palabras, escritas a mano e impresionadas en el primer término del encuadre, son lo único que le pertenece a Bill en el universo de It's such a beautiful day. Y merece la pena señalarlo: ni siquiera la acción de perdonar es suya. Bill, no dice Yo te perdono. Muy al contrario, la fuente de su perdón no pertenece al hombre.

\subsection{Narradores y punto de vista}

Como ya señalábamos al principio del capítulo, el análisis de los distintos niveles de narración sobre los que se levanta It's such a beautiful day es uno de los ejercicios más estimulantes que se ha propuesto en el cine de animación de los últimos años. Ciertamente, parte de la culpa la tiene la introducción por parte de Hertzfoldt de una suerte de narrador omnisciente, extradiegético, sobre el que se sitúa gran parte de la problemática central de la cinta: la comprensión de la enfermedad de Bill, de sus síntomas y de las vivencias que entraña.

Pero merece la pena proceder sistemáticamente. Para ello, y como ya anunciamos, nos apoyaremos en la descripción metodológica propuesta por Gaudreault y Jost y posteriormente ampliada y matizada por Gómez Tarín.

En primer lugar, por tanto, merece la pena pensar It's such a beautiful day como una suerte de enunciación profundamente autoconsciente. De hecho, esa autoconsciencia resulta fascinante en tanto prescinde voluntariamente de cualquier proceso de borrado sobre su propia presencia, incorporando sobre la superficie de la pantalla todo tipo de marcas que denuncian la presencia del Meganarrador. Así, desde la propia artificialidad de la técnica animada hasta los efectos que "erosionan" su propio trazo (borraduras, manchas, gotas de agua que resbalan en capas sobre las figuras que se deslizan por el frame...), el enunciador prescinde voluntariamente de cualquier deuda con un hipotético planteamiento realista.

Sin embargo, el proceso de disposición de los elementos narrativos por el propio Meganarrador no está únicamente vinculado con la ordenación -como ya hemos visto, caótica pero precisa al mismo tiempo- de los núcleos de la historia en disposición estructural, con su consiguiente división de espacio y tiempo. Antes bien, hay una relación íntima entre la enfermedad de Bill y el propio proceso "experiencial” propuesto por el propio control de la enunciación. Dicho todavía con mayor claridad: durante la representación de las crisis de Bill, los mecanismos enunciativos, literalmente, se descontrolan. No solo se utilizan técnicas intrusivas contra el espectador heredadas de los creadores de vanguardias (flashes, extrañas sobreexposiciones de términos visuales, erosiones mediante fuego de los materiales dispuestos sobre el marco...), sino que 
se propone toda una reformulación de su propio lenguaje fílmico para dar cuenta del horror, el vértigo y la sensación de descontrol que acompaña el proceso mismo de la enfermedad.

Por eso decíamos al principio del artículo que la defensa misma de la dignidad del enfermo mental es, en esta cinta, realmente coherente con las normas del propio decir cinematográfico. No se vale de técnicas melodramáticas ya establecidas ni de estilemas de género para intentar retratar y forzar una empatía precipitada y profundamente discutible desde una perspectiva ética. Antes bien, es la propia escritura-es decir, el propio Meganarrador-el que intenta explorar las consecuencias experienciales de la enfermedad mediante el estricto recurso de los recursos narrativos audiovisuales. Si como señaló Tecla González Hortigüela “la teoría de la enunciación debe conformarse como una teoría de la experiencia del sujeto en su confrontación con el lenguaje” (2009: 153), entonces aquí podemos señalar que el propio lenguaje fílmico de Hertzfeldt se pone al servicio de la mostración de una experiencia que, por su propia naturaleza, está precisamente herida en el plano del lenguaje, o si se prefiere, en el plano del sentido.

Lo que nos lleva, lógicamente, al problema del narrador que se incorpora inmediatamente por debajo del Meganarrador y que está representado por esa voz que escuchamos durante toda la cinta y a la que hemos hecho referencia en varias ocasiones. Como sugeríamos hace unos párrafos, ante la disposición caótica, apasionada y profundamente emocional de materiales que propone el Meganarrador, la función del narrador omnisciente parece ser intentar ordenar, explicar, dotar de un cierto sentido. Su palabra funciona como una suerte de "hablador soberano" (Aumont y Marie, 1990: 160), en tanto no solo conoce los acontecimientos, sino que además es capaz de ahondar en los sentimientos, las emociones, los miedos y las topografías de la angustia de Bill y de aquellos que le rodean. Sin embargo -y aquí se encuentra una de las claves más precisas de la película-, la disposición de los acontecimientos se transmite de manera completamente desapasionada, precisa, exenta de cualquier tipo de añadido melodramático.

El narrador no se permite el lujo de guiar mediante su presencia el trayecto emocional del espectador. Se permite pequeños juicios de valor en torno a los personajes secundarios, aunque nunca sabremos a ciencia cierta si le pertenecen o si más bien son reflexiones personales del propio Bill que él mismo encarna. Describe con la misma precisión un sueño terrible del protagonista, el dolor de uno de los enfermos que acompañan a Bill en la clínica, las alucinaciones auditivas o visuales del protagonista... Su presencia inunda el metraje casi por completo, a excepción de las voces de los médicos que aparecen en momentos aislados de la cinta -generalmente para intentar animar a Bill en momentos de gran agonía corporal- o de la máquina de su compañero de cuarto, que repite sistemáticamente I'm in pain (Estoy sufriendo).

Digamos, por lo tanto, que la presencia del narrador en el transcurso de It's such a beautiful day tiene dos límites muy marcados: el primero, como hemos visto, es el de la agonía física. El segundo es el de la propia muerte de Bill. Cuando, al final del tercer fragmento, Bill se tumba en un parque, el narrador por primera vez abandona su rol principalmente expositivo y se arroja en un discurso bien diferente: 
[Bill] a veces canta y a veces llora, y de pronto se da cuenta de que la parte izquierda de su cuerpo ya no responde, es insensible, pero lo único que desea es seguir conduciendo (...) Es un día tan hermoso... Espera un momento. No va a morir. No puede morir. No, no, no, de ninguna manera. Bill, levántate. No puede morir. No va a morir. Nunca morirá. ¿Bill? ${ }^{10}$

El narrador maneja con tranquilidad la tercera persona del singular durante todo el metraje, incluso cuando el cénit del dolor del protagonista llega a su auge. Sin embargo, cuando se pronuncia, como si fuera un arcano, el nombre de la cinta (Es un día tan hermoso - It's such a beautiful day) es precisamente cuando la muerte de Bill se anuncia como irremediable. El narrador, en un gesto claramente unamuniano, carga contra el propio Meganarrador, contra la lógica narrativa, incluso contra las expectativas del espectador mismo. Bill no puede morir. Le resulta insoportable la idea misma de que, después de hacerse cargo mediante el lenguaje del terrible vía crucis experimentado por el protagonista, todo acabe allí, en ese parque, en mitad de un día hermoso. Dicho todavía con más claridad: el narrador comprende que, si Bill muere, habrá fracasado en su misión de dotar de un sentido a su propio sufrimiento mediante la captación en palabras.

De ahí que la cinta solo pueda terminar con esa suerte de negación del tiempo, de viaje épico completamente desesperado en el que Bill se eleva contra la muerte misma y encuentra el conocimiento, el amor y la lógica de su experiencia. La pantalla en negro sobre la que el narrador repetía una y otra vez No puede morir vuelve a iluminarse y, durante apenas dos minutos, Hertzfeldt propone la posibilidad de que, más allá de ese umbral de sufrimiento puro sobre el que nosotros no podemos escribir ningún sentido, se desvele la riqueza del redescubrimiento del mundo, del Otro y de la verdad.

\section{Referencias bibliográficas}

Aristóteles. (1974): Poética. Madrid: Gredos.

Augé, M. (2005): Los “no lugares”, espacios del anonimato: una antropología de la sobremodernidad. Madrid: Gedisa. Aumont, J., \& Marie, M. (1990): Análisis del film. Barcelona: Paidós.

Bellour, R. (2013): El cuerpo del cine. Hipnosis, emociones, animalidades. Santander: Shangrila.

Bergson, H. (1925): Ensayo sobre los datos inmediatos de la conciencia. Madrid: Francisco Beltrán.

Bordwell, D. (1995): El Significado del filme: inferencia y retórica en la interpretación cinematográfica. Barcelona: Paidós. Burch, N. (1987): El Tragaluz del infinito: contribución a la geneaología del lenguaje cinematográfico. Madrid: Cátedra. Burleigh, M. (1994): Death and deliverance. "Euthanasia” in Germany 1900-1945. Cambridge: Cambridge University Press. Campbell, J. (2005): El Héroe de las mil caras: psicoanálisis del mito. Madrid: Fondo de Cultura Económica de España.

10 Traducción del autor. 
Chown, M. (2007): El zoo cuántico. Guía turística del interminable universo. Barcelona: La liebre de Marzo.

Cueto, R. (2005): “Ars moriendi. Breve historia de la representación de la muerte en el cine”, en V. Dominguez (Ed.): Tabú: La sombra de lo prohibido, lo innombrable y contaminante. Gijón: Festival de Gijón, pp. 25-54.

Cullberg, J. (2007): Psicosis: una perspectiva integradora. Madrid: Fundación para la investigación y el tratamiento de la Esquizofrenia y otros trastornos.

Didi-Huberman, G. (2007): La Invención de la histeria: Charcot y la iconografía fotográfica de la Salpêtrière. Madrid: Cátedra.

Didi-Huberman, G. (2014): Pueblos expuestos, pueblos figurantes. Buenos Aires: Manantial.

Esqueda Verano, L., y Cuevas Álvarez, E. (2012): “Entre la huella y el índice: relecturas contemporáneas de André Bazin”, Área Abierta, n. 13, pp. 1-12.

Field, S. (2001): El Libro del guion: fundamentos de la escritura de guiones: una guía paso a paso, desde la primera idea hasta el guión acabado. Madrid: Plot.

Foucault, M. (1978): Vigilar y castigar: nacimiento de la prisión. México: Siglo XXI Ediciones.

García, S., \& Sorolla, T. (2014): “Morfologías de nuestros áridos días felices”, L’Atalante. Revista de Estudios Cinematográficos, n. 17, pp. 46-52.

Goetz, A. (2014): Los que sobraban. Historia de la eutanasia social en la Alemania nazi, 1939-1945. Barcelona: Editorial Planeta.

Gómez Tarín, F. J. (2011): Elementos de narrativa audiovisual: expresión y narración. Santander: Shangrila.

González Hortigüela, T. (2009): “Aproximación a la problemática de la enunciación: el lugar del sujeto en el texto artístico", Revista Zer, n. 14(27), pp.149-163.

González Requena, J. (2002): Los tres reyes magos: La eficacia simbólica. Madrid: Editorial Akal.

Hart, O. van der, Nijenhuis, E. R. S., \& Steele, K. (2008): El Yo atormentado: la disociación estructural y el tratamiento de la traumatización crónica. Bilbao: Desclée de Brouwer.

Heidegger, M. (1994): Conferencias y artículos. Barcelona: Ediciones del Serbal.

- (2005): ¿Qué significa pensar? Madrid: Trotta.

- (2009): Ser y tiempo. Madrid: Trotta.

Jost, A., \& Gaudreault, F. (1995): El relato cinematográfico: Ciencia y narratología. Barcelona: Paidós.

Kracauer, S. (1989): Teoría del cine. La redención de la realidad física. Barcelona: Paidós.

Kunz, S. (2012): “The role of Drawing in Animated Films”, International Conference in Ilustration \& Animation, n. 1, pp. 51-66. 
Lacan, J. (2005): De los nombres del Padre. Buenos Aires: Paidós.

Lévinas, E. (1999): Totalidad e infinito: ensayo sobre la exterioridad. Salamanca: Sígueme.

- (2000): De la existencia al existente. Madrid: Arena Libros.

McKee, R. (2002): El Guion: sustancia, estructura, estilo y principios de la escritura de guiones. Barcelona: Alba.

Moreno Martin, F. (2003): El factor humano en pantalla: Un paseo por la psicología desde el patio de butacas. Madrid: Editorial Complutense.

Muñoz, A. y Uriarte, J. (2006): “Estigma y enfermedad mental”, Revista Norte de Salud Mental, n. 26, pp. 49-59.

Orellana, J. y Martínez Lucena, J. (2010): Celuloide posmoderno: narcisismo y autenticidad en el cine actual. Madrid: Encuentro.

Palao Errando, J. A. (2008): “Corredores sin ventana, acrobacias sin red: linealidad narrativa e imaginario hipertextual en el cine contemporáneo", en Tortosa, V. (ed.): Escrituras digitales: Tecnologías de la creación en la era virtual. Alicante: Publicaciones de la Universidad de Alicante, pp. 289-312.

Palao Errando, J. A. (2013): “Contando al otro: el hipernúcleo, una figura clave en la narrativa fílmica postclásica”, L’Atalante. Revista de Estudios Cinematográficos, n. 15, pp. 19-26.

Poseck, B. V. (2007): "Manicomios de cine: la representación de las instituciones mentales y sus procedimientos en la gran pantalla”, Med Cine, n. 3, pp. 57-67.

Propp, V. (1974): Las Raíces históricas del cuento. Madrid: Fundamentos.

Propp, V. (2007): Morfología del cuento. Madrid: Akal.

Prósper Ribes, J. (2008): “La imagen subjetiva”, Revista Área Abierta, n. 20, pp. 1-12.

Rodríguez Serrano, A. (2010). "Sujeto fragmentado: algunas contradicciones del discurso cinematográfico postmoderno", Revista Sphera Publica, n. 10, pp. 43-56.

Rodríguez Serrano, A. (2015): “Construir, habitar, pensar, exterminar. Heidegger y la arquitectura de Auschwitz”, Revista REIA: Revista Europea de Investigación en Arquitectura, n. 3, pp. 153-164.

Rosenbaum, J. (2010): Goodbye Cinema, Hello Cinephilia: Film culture in transition. Chicago: The University of Chicago Press.

Ruiz de Samaniego, A. (2015): Las horas bellas. Escritos sobre cine. Madrid: Abada Editorial.

Sánchez-Escalonilla, A. (2001): Estrategias de guion cinematográfico. Barcelona: Ariel.

Straw, W. (2002): “Reinhabiting lost languages: Guy Maddin`s Careful”, en P. Walz, E. (ed.): Canada’s Best Features. Critical essays on 15 Canadian Films. Amsterdam: Editions Rodopi, pp. 305-320. 
Thys, N. (2013): “Don Hertzfeldt”, 24 Images, n. 163, p. 23.

Vera Poseck, B. (2006): Imágenes de la locura: la psicopatología en el cine. Madrid: Calamar.

Vila, S. (1997): La Escenografia: cine y arquitectura. Madrid: Cátedra.

Vogler, C. (2002): El Viaje del escritor: las estructuras míticas para escritores, guionistas, dramaturgos y novelistas. Barcelona: Ma non troppo.

Wedding, D., Boyd, M., \& Niemiec, R. M. (2005): Movies and mental illness: using films to understand psychopathology. Cambridge: Hogrefe.

Yébenes, P. (2002): Cine de animación en España. Madrid: Ariel.

Zamora Marín, R. (2009): “La enfermedad y el sentido del sufrimiento”, Revista Cubana de Salud Pública, n. 35, pp. 1-15.

Zumalde, I. (2002): Los Placeres de la vista: mirar, escuchar, pensar. Valencia: Institut Valencià de Cinematografia Ricardo Muñoz Suay.

Zumalde, I. (2006): La Materialidad de la forma fílmica: crítica de la (sin)razón postestructuralista. Bilbao: Euskal Herriko Unibertsitatea. Argitalpen Zerbitzua.

Zumalde, I. (2011): La Experiencia fílmica: cine, pensamiento y emoción. Madrid: Cátedra. 